\title{
The effect of gap junctions on the dynamic range in a model of the
} rod photoreceptors layer

\author{
Rodrigo Publio*1, Rodrigo F Oliveira ${ }^{2}$ and Antonio C Roque ${ }^{1}$
}

Address: ${ }^{1}$ Departamento de Física e Matemática, FFCLRP, Universidade de São Paulo Av. Bandeirantes, 3900, 14040-901, Ribeirão Preto, SP, Brazil and ${ }^{2}$ Departamento de Psicologia e Educação, FFCLRP, Universidade de São Paulo Av. Bandeirantes, 3900, 14040-901, Ribeirão Preto, SP, Brazil

Email: Rodrigo Publio* - publio@neuron.ffclrp.usp.br

* Corresponding author

from Sixteenth Annual Computational Neuroscience Meeting: CNS*2007

Toronto, Canada. 7-12 July 2007

Published: 6 July 2007

BMC Neuroscience 2007, 8(Suppl 2):PI8I doi:I0.II86/I47|-2202-8-S2-PI8I

(C) 2007 Publio et al; licensee BioMed Central Ltd.

Recent studies suggest the existence of electrical synapses (gap junctions) in the vertebrate retina, which would be present in at least three different circuits responsible for transmission of rod signals to ganglion cells. In this work we present a computer model of the receptor layer made of 900 biologically realistic rods coupled by gap junctions. The rod model has six types of ionic currents and the connectivity patterns within the receptor layer are based on experimental data available from the literature. We study the role of the gap junction coupling on the enhancement of the dynamic range of the photoreceptor layer beyond the dynamic range of a layer made of uncoupled rods. Simulation results show that the presence of gap junctions in early stages of signal processing could increase the dynamic range of the photoreceptor layer by preventing early saturation. 